\title{
Endometrial polyps in female allograft recipients with abnormal bleedings
}

\author{
Dariusz Rajski, Katarzyna Bobrowska, Bronisława Pietrzak, Mirosław Wielgoś, Paweł Kamiński \\ Ist Department of Obstetrics and Gynecology, Medical University of Warsaw, Poland
}

\begin{abstract}
Introduction: Endometrial polyps are a common focal endometrial pathology, with abnormal uterine bleeding (AUB) as a predominant symptom. Although the great majority of cases are benign, premalignancy or malignancy may develop within the polyp. The need for chronic immunosuppressive therapy in solid organ transplanted patients is associated with a significantly increased risk of malignant lesions.

Aim of the study was to evaluate the risk of endometrial polyps in solid organ transplanted women with abnormal uterine bleeding.

Material and methods: The retrospective analysis of 125 cases of AUB in allograft recipients and 200 consecutive cases of AUB in patients from the general population was performed. Pathological findings from dilatation and curettage were analyzed and compared between the groups.

Results: Endometrial polyps were the only pathological findings in $12 \%$ and $21.5 \%$ of cases from the study and the control groups, respectively. In each of the groups, one case of endometrial cancer coexisted with an endometrial polyp. If cases of endometrial polyps coexisting with endometrial hyperplasia were taken into account, the rate of endometrial polyps was similar to that observed in the general population ( $20 \% \mathrm{vs} .21 .5 \%$, respectively).

Conclusions: Chronic immunosuppression, associated with an increased risk of malignancy, does not increase the risk of endometrial polyps among female graft recipients.
\end{abstract}

Key words: endometrial polyp, abnormal uterine bleeding, renal transplantation, liver transplantation, D\&C.

\section{Introduction}

Endometrial polyps are a common focal endometrial pathology. The lesion can cause abnormal uterine bleedings (intermenstrual bleeding, heavy and prolonged menstrual bleeding), impede fertility or may remain asymptomatic. The incidence of polyps rises with age. Although the great majority of cases are benign, premalignancy or malignancy may develop within the polyp. The risk of malignancy is increased in women, especially menopausal women [1], with abnormal uterine bleedings and in lesions greater than 10-15 mm [1, 2]. In the study of Costa-Paiva et al., the frequency of premalignancy and malignancy in polyps was $1.6 \%$ and $2.5 \%$, respectively, among patients with polyps associated with abnormal uterine bleedings [3].

Patients after solid organ transplantation require chronic immunosuppressive therapy, which is known to be associated with an increased risk of premalignancy and malignancy [4]. Abnormal uterine bleedings occur more frequently in female solid organ recipients than in the general population and always need to be followed by histopathological assessment of endometrial samples.
The aim of the study was to evaluate the incidence of endometrial polyps in patients after solid organ transplantation with abnormal uterine bleeding.

\section{Material and methods}

Medical files of women diagnosed with abnormal uterine bleeding at the $1^{\text {st }}$ Department of Obstetrics and Gynecology, Medical University of Warsaw in 19962008 were retrospectively analyzed. One hundred and five patients with abnormal uterine bleeding after solid organ transplantation were identified and included in the study group. A significant number of patients had recurrent AUB followed by two or even three diagnostic procedures performed within the analyzed period of time. If the time between the procedures was more than one year, there could have been differences in the patient's weight, menopausal status, treatment and immunosuppressive regimen, thus the cases were counted separately, which eventually gave the number of 125 cases. The control group consisted of 200 consecutive patients from the general population diagnosed with abnormal uterine bleeding in 2008. Characteristics of 


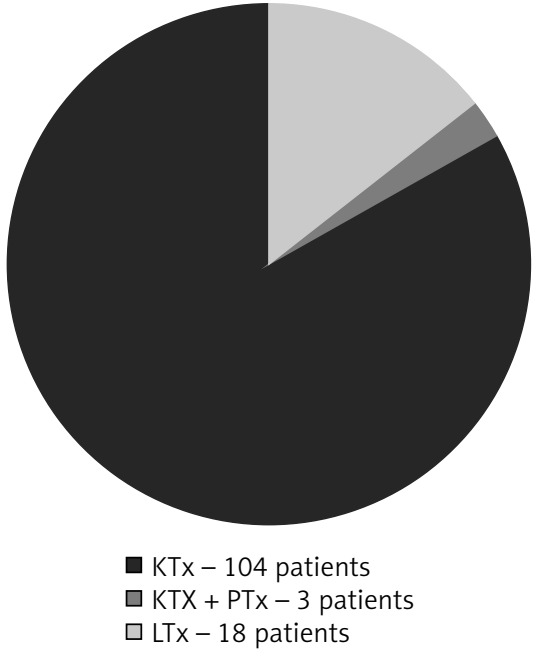

KTx - kidney transplantation, PTx - pancreas transplantation, LTX - liver transplantation

Fig. 1. Type of organ transplantation in the study group

the study group and the control group are presented in Table I. The type of organ transplantation in the study group is shown in Figure 1. Dilatation and curettage was performed in both groups followed by pathological evaluation of endometrial and cervical samples. Results were statistically analyzed.

\section{Results}

Endometrial polyps were the only pathological findings in 15 cases (12\%) from the study group and in 43 cases $(21.5 \%)$ from the control group. Regarding the type of organ transplantation, polyps were diagnosed in 14 cases $(11 \%)$ after renal transplantation versus 1 case (17\%) after liver transplantation. In 21\% (4 cases) of organ recipients with AUB there were endometrial hyperplasia and endometrial polyps as coexisting pathologies. If cases of endometrial polyps coexisting with endometrial hyperplasia were taken into account, the rate of endometrial polyps was compared to that observed in the general population ( $20 \%$ vs. $21.5 \%$, respectively). In one case from the study group and in one case from the control group, endometrial polyp was associated with the coexisting endometrial cancer (Table II).

Graft recipients with endometrial polyps were younger compared to patients from the control group (46.36 SD 9.87 vs. 54.25 SD 9.07 years). Coexisting morbidities, including hypertension and diabetes mellitus, were observed more frequently among graft recipients (78.6\% vs. $44.2 \%$ and $35.7 \%$ vs. $4.6 \%$ of cases, respectively). The evaluation of risk with the use of a logistic regression model showed that the age $>45$ years and pregnancy in obstetrical history were associated with a decreased risk of endometrial polyps (OR 0.448, Cl: 0.200-1.005 and OR 0.504, Cl: 0.250-1.018).
Tab. I. Characteristics of the study group and control group

\begin{tabular}{lcc}
\hline Factors & $\begin{array}{c}\text { Study group } \\
\text { Mean (SD) }\end{array}$ & $\begin{array}{c}\text { Control group } \\
\text { Mean (SD) }\end{array}$ \\
\hline Age & $42.79(8.05)$ & $52.39(9.09)$ \\
\hline BMI & $24.95(4.56)$ & $27.23(5.40)$ \\
\hline Menarche (y.o) & $13.47(1.52)$ & $13.48(1.48)$ \\
\hline Menopause (y.o) & $48.11(3.03)$ & $50.20(4.07)$ \\
\hline $\begin{array}{l}\text { Labors (no) } \\
\text { Abortion (no) }\end{array}$ & $1.39(1.31)$ & $1.62(0.98)$ \\
\hline $\begin{array}{l}\text { Length of menstrual cycles } \\
\text { (days) }\end{array}$ & $30.60(11.22)$ & $28.87(3.56)$ \\
\hline $\begin{array}{l}\text { Length of regular cycles } \\
\text { (days) }\end{array}$ & $28.07(2.28)$ & $28.01(1.96)$ \\
\hline $\begin{array}{l}\text { Length of irregular cycles } \\
\text { (days) }\end{array}$ & $43.90(23.91)$ & $31.56(5.62)$ \\
\hline \begin{tabular}{l} 
Length of menses (days) \\
\hline
\end{tabular} & $5.10(1.65)$ & $5.48(1.54)$ \\
\hline
\end{tabular}

\section{Discussion}

The growing number of organ transplantations across the world as a generally accepted form of treatment of end-stage organ failure is followed by the growing number of recipients treated with immunosuppressive agents. Many studies indicate the increased rate of certain types of tumors among patients after solid organ transplantation [5-7]. Neoplasm is one of the leading causes of death in this group of patients. Renal recipients, the most numerous subgroup of transplant patients, are observed to have a 3 times higher risk of 25 types of tumors [8]. The exact mechanisms of carcinogenesis among organ recipients are not clear. Viral infections $[9,10]$ and chronic immunosuppression, which impair anti-tumour protective mechanisms [11, 12] are believed to be the leading causes of malignancy. Other factors that may play a role are UVA and UVB radiation [13] and less known mechanisms.

Women after organ transplantation form a specific group of patients. Higher levels of estrogens with normal levels of gonadotropins [14] and lower levels of progesterone in the luteal phase of the menstrual cycle have been reported in female graft recipients. Higher levels of estrogen are likely to be related to the impaired metabolism of steroid hormones [15]. Due to multidrug therapy, including chronic immunosuppression as well as higher vulnerability to viral infections and secondary morbidities, those patients have a higher risk of neoplasm [16-19]. Female allograft recipients frequently present with abnormal uterine bleedings that concern both the patient and the gynecologist. Given the increased risk of neoplasms, the presence of disturbing symptoms such as AUB has to be followed with careful diagnostic procedures with endometrial sampling. 
Tab. II. Histopathological findings in both groups of patients

\begin{tabular}{lccc}
\hline & Study group, $n$ (\%) & Control group, $n$ (\%) & $p$ \\
\hline Diagnosis & & & NS \\
\hline Proliferative endometrium & $42(33.6 \%)$ & $70(35.0 \%)$ & $p \leq 0.05$ \\
\hline Atrophic endometrium & $6(4.8 \%)$ & $44(22.0 \%)$ & $p \leq 0.05$ \\
\hline Endometrial hyperplasia without atypia & $54(43.2 \%)$ & $29(14.5 \%)$ & NS \\
\hline Endometrial hyperplasia with atypia & $1(0.8 \%)$ & $2(1.0 \%)$ & NS \\
\hline Endometrial cancer & $1(0.8 \%)$ & $5(2.5 \%)$ & $p \leq 0.05$ \\
\hline Endometrial polyp & $15(12.0 \%)$ & $43(21.5 \%)$ & NS \\
\hline Submucosal myoma & $3(2.4 \%)$ & $4(2.0 \%)$ & NS \\
\hline Retained products of conception & $3(2.4 \%)$ & $1(0.5 \%)$ & $p \leq 0.05$ \\
\hline Cervical polyp* & $6(4.8 \%)$ & $3(1.5 \%)$ & NS \\
\hline Cervical cancer & $0(0.0 \%)$ & $2(1.0 \%)$ & NS \\
\hline Cervical dysplasia* & $5(4.0 \%)$ & $2(1.0 \%)$ & NS \\
\hline Vulvar dysplasia* & $1(0.8 \%)$ & $0(0.0 \%)$ & \\
\hline
\end{tabular}

*Additional finding, coexisting with the basic finding

Endometrial polyp is one of pathological lesions associated with abnormal uterine bleedings. Etiology of endometrial polyps is complex. Hormonal abnormalities, especially related to coexisting obesity and hypertension [20], improper angiotensin and progesterone receptor expression [21, 22], certain drugs (tamoxifen, angiotensin convertase inhibitors etc.) $[23,24]$ and genetic factors are taken into consideration. Polyps might be a solitary or multiple lesion, with a peduncular or based shape. The sizes of endometrial polyps vary from millimeters to centimeters and the larger sizes of polyps are believed to be associated with a higher risk of malignancy [2, 3].

Suspicion of the endometrial polyp is based on sonographic examination. The polyp on transvaginal sonography is imaged as a hyperechoic lesion surrounded by a hypoechoic endometrial layer or as a nonspecific thickness of endometrial mucosa. Sensitivity of imaging might be elevated on three-dimensional or saline infusion sonography [25] or when power Doppler displays a single blood vessel supplying the focal lesion [26]. Verification of sonographic findings is possible during hysteroscopy, considered as the most sensitive method of endometrial polyp detection [27]. This method, especially its office modification of Bettocchi, has become more frequently used in female allograft recipients. However other conservative methods of endometrial sampling, mainly dilatation and curettage, are still common.

In our study, endometrial polyp as a single cause of abnormal uterine bleeding was found less frequently among women after solid organ transplantation compared to the control group. However, if cases of endo- metrial polyps coexisting with endometrial hyperplasia were taken into account, the rate of endometrial polyps was similar to that observed in the general population ( $20 \%$ vs. $21.5 \%$, respectively). A high rate of endometrial hyperplasia has been already observed among female allograft recipients, what is believed to be associated with inappropriate estrogen stimulation of endometrial tissue and chronic immunosuppressive therapy.

In conclusion, chronic immunosuppression, associated with an increased risk of malignancy, does not increase the risk of endometrial polyps among female graft recipients. In the case of abnormal uterine bleedings in women after organ transplantation, dilatation and curettage can serve as a primary diagnostic method of endometrial sampling.

\section{Disclosure}

Authors report no conflicts of interest.

\section{References}

1. Wang JH, Zhao J, Lin J. Opportunities and risk factors for premalignant and malignant transformation of endometrial polyps: management strategies. J Minim Invasive Gynecol 2010; 17: 53-58.

2. Lasmar BP, Lasmar RB. Endometrial polyp size and polyp hyperplasia. Int J Gynaecol Obstet 2013; 123: 236-239.

3. Costa-Paiva L, Godoy CE Jr, Antunes A Jr, et al. Risk of malignancy in endometrial polyps in premenopausal and postmenopausal women according to clinicopathologic characteristics. Menopause 2011; 18: 1278-1282.

4. Penn I. Cancer is a complication of severe immunosuppression. Surg Gynecol Obstet 1986; 162: 603.

5. Penn I. Cancers of anogenital region in renal trans plant recipients. Cancer 1986; 58: 611-615. 
6. Penn I. Incidence and treatment of neoplasia after transplantation. J Heart Lung Transplant 1993; 12: S328-336.

7. KaufFman HM, Cheriks WS, McBride MA, et al. Post-transplant de novo malignancies in renal transplant recipients: the past and the present. Transpl Int 2006; 19: 607-620.

8. Vajdic CM, Mc Donald SP, McCredie MR, et al. Cancer incidence before and after kidney transplantation. JAMA 2006; 296: 2823-2831.

9. Bouwes Bavinck JN, Berkhout RJM. HPV infection and immunosuppression. Clin Dermatol 1997; 15: 427-437.

10. Tsao L, His ED. The clinicopathologic spectrum of posttransplant lymphoproliferative disorders. Arch Pathol Lab Med 2007; 131: 1209-1218.

11. Martinez OM, de Gruijl FR. Molecular and immunologic mechanisms of cancer pathogenesis in solid organ transplant recipients. Am J Transp 2008; 8: 2205-2211.

12. Guba M, Graeb C, Jauch KW, et al. Pro-and anti-cancer effects of immunosuppressive agents used in organ transplantation. Transplantation 2004; 77: 1777-1782.

13. Yarosh DB, Pena AV, Nay SL, et al. Calcineurin inhibitors decrease DNA repair and apoptosis in human keratinocytes following ultraviolet $B$ irradiation. J Invest Dermatol 2005; 125: 1020-1025.

14. de Koning ND, Haagsma EB. Normalization of menstrual patterns after liver transplantation: consequences for contraception. Digestion 1990 46: 239-241

15. Mass K, Quint EH, Punch MR, et al. Gynecological and reproductive function after liver transplantation. Transplantation 1996; 62: 476-479.

16. Kaminski P, Bobrowska K, Pietrzak B, et al. Gynecological issues after organ transplantation. Neuro Endocrinol Lett 2008; 29: 852-856.

17. Husslein H, Breitenecker G, Tatra G. Premalignant and malignant uterine changes in immunosuppressed renal transplant recipients. Acta Obstet Gynecol Scand 1978; 57: 73-78.
18. Birkeland SA, Løkkegaard H, Storm HH. Cancer risk in patients on dialysis and after renal transplantation. Lancet 2000; 355: 1886-1887.

19. Engels EA, Pfeiffer RM, Fraumeni JF Jr, et al. Spectrum of cancer risk among US solid organ transplant recipients. JAMA 2011; 306: 18911901

20. Onalan R, Onalan G, Tonguc E, et al. Body mass index is an independent risk factor for the development of endometrial polyps in patients undergoing in vitro fertilization. Fertil Steril 2009; 91: 1056-1060.

21. de Carvalho S, Campaner AB, Lima SM, et al. Differential expression of estrogen and progesterone receptors in endometrial polyps and adjacent endometrium in postmenopausal women. Anal Quant Cytol Histol 2011; 33: 61-67.

22. Zitao L, Kuokkanen S, Pal L. Steroid hormone receptor profile of premenopausal endometrial polyps. Reprod Sci 2010; 17: 377-383.

23. Indraccolo $U$, Matteo $M$, Greco $P$, et al. ACE inhibitors and angiotensin receptor blockers could promote the onset of endometrial polyps in hypertensive women. Int J Clin Pharmacol Ther 2013; 51: 963-968.

24. Cohen I. Endometrial pathologies associated with postmenopausal tamoxifen treatment. Gynecol Oncol 2004; 94: 256-266.

25. Bingol B, Gunenc Z, Gedikbasi A, et al. Comparison of diagnostic accuracy of saline infusion sonohysterography, transvaginal sonography and hysteroscopy. J Obstet Gynaecol 2011; 31: 54-58.

26. Adel M, Kandil M, Abo-Elnasr M, et al. Three-dimensional sonohysterography may replace hysteroscopy for women with perimenopausal bleeding. Climacteric 2014; 17: 55-59.

27. Elfayomy AK, Habib FA, Alkabalawy MA. Role of hysteroscopy in the detection of endometrial pathologies in women presenting with postmenopausal bleeding and thickened endometrium. Arch Gynecol Obstet 2012; 285: 839-843. 